\title{
A prospective randomized assessment of quality of life between open and robotic hysterectomy in early endometrial cancer
}

Evelyn Lundin, Ninnie Borendal Wodlin, Lena Nilsson and Preben Kjölhede

The self-archived postprint version of this journal article is available at Linköping University Institutional Repository (DiVA):

http://urn.kb.se/resolve?urn=urn:nbn:se:liu:diva-158346

N.B.: When citing this work, cite the original publication.

Lundin, E., Borendal Wodlin, N., Nilsson, L., Kjölhede, P., (2019), A prospective randomized assessment of quality of life between open and robotic hysterectomy in early endometrial cancer, International Journal of Gynecological Cancer, 29(4), 721-727. https://doi.org/10.1136/ijgc-2019000285

Original publication available at:

https://doi.org/10.1136/ijgc-2019-000285

Copyright: BMJ Publishing Group

http://group.bmj.com/ 
Original Research Article

\section{Postoperative recovery after robotic hysterectomy in early endometrial cancer. An open randomized controlled trial.}

by

Evelyn Serreyn Lundin ${ }^{1}$, MD, Ninnie Borendal Wodlin ${ }^{1}$, MD, PhD, Lena Nilsson ${ }^{2}, \mathrm{MD}$, $\mathrm{PhD}$, Preben Kjølhede ${ }^{1}, \mathrm{MD}, \mathrm{PhD}$

\section{$\underline{\text { Affiliations }}$}

${ }^{1}$ Children and Women's health, Department of Clinical and Experimental Medicine, Linköping University, Linköping, Sweden

${ }^{2}$ Department of Anesthesiology and Intensive Care, and Department of Medical and Health Sciences, Linköping University, Linköping, Sweden

Corresponding author:

Evelyn Serreyn Lundin, MD

Department of Obstetrics and Gynecology, University Hospital

58185 Linköping

Sweden

Phone +46101030000

E-mail: Evelyn.Lundin@regionostergotland.se

\section{Funding}

The study was supported financially by grants from the Medical Research Council of South

East Sweden, Linköping University and the County Council of Östergötland.

\section{Conflict of interest statement}

None of the authors has any conflict of interest to declare. 


\section{Abstract}

Objective: To determine whether postoperative recovery differs between women operated with robotic and abdominal hysterectomy for low-risk endometrial cancer.

Material and Methods: At a Swedish tertiary referral university hospital, 50 women with lowrisk endometrial cancer scheduled for radical surgery between February 2012 and May 2016 were included in an open randomized controlled trial; 25 women were allocated to robotic and 25 to abdominal hysterectomy. Surgery was performed according to principles for minimal invasive surgery. Anesthesia and perioperative care followed a standardized enhanced recovery after surgery program in both groups. The EuroQol Group form EQ-5D and the Short Form-36 evaluated the health-related quality of life. The Swedish Postoperative Symptoms Questionnaire assessed symptoms preoperatively, daily for seven days from the day of surgery, and then weekly until six weeks postoperatively. Data were analyzed by means of non-parametric tests and repeated measures ANOVA. To evaluate the timedependent occurrence of complications Kaplan-Meier survival and Cox proportional-hazard models were used.

Results: Women in the robotic hysterectomy group recovered significantly faster $(p=0.01)$ in the EQ-5D health index, and reached their preoperative level nearly two weeks earlier than the abdominal group. Differences regarding improvement in health-related quality of life (Short Form-36) comprised general health and social functioning only, and were in robotic hysterectomy favor. Consumption of analgesics, pain intensity and symptom sum score postoperatively and length of hospital stay (robotic: median 53 hours versus abdominal: median 51 hours, $\mathrm{p}=0.29$ ) were equal. Occurrence of complications was an independent risk factor and influenced most of the outcome measures adversely.

Conclusion: Robotic hysterectomy in an enhanced recovery after surgery setting in the treatment of early endometrial cancer leads to a faster recovery in health-related quality of life 
than abdominal hysterectomy, with an equivalent length of hospital stay in both groups. Perioperative complications strongly influence the health-related quality of life.

Keywords: endometrial cancer, postoperative symptoms, recovery, quality of life, robotic hysterectomy.

\section{Precis}

Robotic hysterectomy provided a faster recovery in patient-reported quality of life than abdominal hysterectomy in low-risk endometrial cancer treatment using ERAS. Perioperative complications strongly influenced the recovery.

\section{Highlights}

- Robotic hysterectomy gives a faster recovery in quality of live than abdominal hysterectomy.

- Hospital stay, overall postoperative discomfort and analgesic consumption were similar.

- Perioperative complications strongly influenced the recovery. 


\section{Introduction}

Many factors influence recovery after surgery. The purpose of enhanced recovery after surgery programs is to facilitate recovery and reduce recovery time. The multimodal enhanced recovery after surgery (ERAS) concept includes a variety of medical and non-medical components that contribute to improving the postoperative recovery. ${ }^{1-3}$ The program recommend the use of minimal invasive surgery when possible because of the clinical benefits. Randomized trials and a meta-analysis comparing laparoscopy with laparotomy in treating women with endometrial cancer have shown a lower rate of complications and shorter hospital stay in the laparoscopy group although none of the included trials were conducted in enhanced recovery after surgery programs. ${ }^{4,5}$ The majority of women with endometrial cancer continued to be treated by laparotomy until the introduction of the robotic technology. ${ }^{6}$ Although the robotic system (Da Vinci ${ }^{\circledR}$, Intuitive Surgical Systems, Sunnyvale, California) seems to be clinically effective, controversies have arisen about the benefits of the technique in relation to the increased costs.

Randomized trials using enhanced recovery after surgery are still required in order to quantify the benefits on perioperative outcome and risks associated with robotic surgery to draw definitive conclusions about the technique compared with open surgery. ${ }^{7,8}$ Only a few randomized trials have recently been published comparing robotic and abdominal surgery in endometrial cancer. ${ }^{9,10}$ When comparing surgical interventions it is important to keep all other perioperative factors similar in the groups and to use the best evidence-based methods for preventing and treating all perioperative discomfort.

The aims of this open, randomized controlled trial were to determine as primary outcome whether women with low-risk endometrial cancer operated with robotic hysterectomy in an enhanced recovery after surgery program had a faster postoperative recovery measured by patient-reported health-related quality of life, and as secondary 
outcomes, whether they had fewer postoperative symptoms, lower analgesic consumption and shorter hospitalization than women operated with abdominal hysterectomy. 


\section{Material and methods}

A prospective open randomized controlled study of women with low-risk endometrial cancer, comparing robotic and abdominal hysterectomy in an enhanced recovery after surgery program was undertaken at the Department of Obstetrics and Gynecology at the University Hospital in Linköping, Sweden.

Women admitted for surgical treatment of stage I, endometrial cancer (endometrioid adenocarcinoma, grade 1 and 2) and scheduled for hysterectomy, bilateral salpingooophorectomy with peritoneal washings between February 2012 and May 2016 were asked to participate in the study. Additional medical inclusion criteria were: women $\geq 18$ years of age, speaking Swedish fluently, with WHO-performance status $\leq 2$. Exclusion criteria were: laparoscopic approach not considered suitable; a planned midline incision; more extensive surgery than hysterectomy and bilateral salpingo-oophorectomy was planned; any condition that excluded the woman from having intrathecal morphine analgesia; immunosuppressive medication; physically disabled; severe psychiatric or mental disorder.

The web program SISA (http://home.clara.net/sisa/randmiz.htm) generated a balanced randomization with sequences into blocks of ten with an allocation ratio 1:1 to robotic or abdominal hysterectomy. The woman was informed about the allocated method after signing an informed consent The participants had routine preoperative evaluation ${ }^{11}$ and received identical information about the care and perioperative advice according to the enhanced recovery after surgery program.

Prior to the general anesthesia the women received an intrathecal combination of bupivacaine $20 \mathrm{mg}$ and morphine $0.2 \mathrm{mg}$ (women older than 70 years bupivacaine $15 \mathrm{mg}$ and morphine $0.1 \mathrm{mg})$. The general anesthesia was standardized: induction with fentanyl and propofol, intubation facilitated with rocuronium and maintenance with sevoflurane. To prevent hypothermia, insufflation of heated $\mathrm{CO}_{2}$ was used in the robotic surgery. In the 
laparotomy group a hot air blanket was applied to the upper part of the body. Local anesthetic was injected in the area of the skin incision in both groups.

The abdominal hysterectomy was conducted through a transverse lower abdominal skin incision. The robotic hysterectomy was performed with four robotic ports and three robotic arms using the $d a V i n c i^{\circledR}$, Surgery System. In both groups a bipolar vessel sealing device was used. Preoperatively the women received a single dose prophylactic antibiotic and routine thrombosis prophylaxis. All operations were performed by gynecological oncology surgeons; one skilled robotic surgeon operated robotically and six surgeons performed the abdominal surgery. The robotic gynecological surgery was introduced in our hospital 2010 . The access to robotic surgery was restricted to one day per week outside holiday periods. Consequently, the number of women that could be subjected to robotic hysterectomy was limited.

The women received analgesics comprising oral paracetamol and diclofenac as long as needed. Rescue IV morphine, ketobemidon or oral oxycodone was given if necessary.

To quantify the amount of non-opioid analgesics given, the WHO-defined daily dose (DDD) methodology was used. ${ }^{12}$ All opioids given, independent of administration route and including the intrathecal morphine, were registered and converted into an equivalent intravenously morphine dose. ${ }^{13}$

The standardized criteria for discharge comprised that the woman was able to walk around, tolerated a normal diet, had sufficient pain relief with oral analgesics $(\leq 4$ on a numeric rating scale from 0 to 10 ), had voided spontaneously with less than $150 \mathrm{ml}$ residual urine and showed no signs of mechanical bowel obstruction. These criteria were checked twice daily. The time of arrival at the operating theater and the time of discharge from the ward were registered. The length of hospital stay as the time to when the discharge criteria were met could be calculated. 
Perioperative adverse events, in the text designated as complications, were registered during the hospital stay. After discharge, the women registered the analgesic consumption in a diary. The research nurse called the patient the day after discharge and then once weekly until the six-week outpatient visit to detect complications and to remind the participant to complete the questionnaires. At the six-week postoperative visit, the emphasis was on registration of complications and recovery.

Two validated generic forms, the EuroQol Group EQ-5D ${ }^{14}$ and the Short Form-36, ${ }^{15}$ were used to assess the health-related quality of life. The EQ-5D form was completed preoperatively, daily during the first week after surgery, and then once weekly until the sixweek postoperative visit. The Short Form-36 was completed twice, preoperatively and six weeks postoperatively.

The Swedish Postoperative Symptom Questionnaire, ${ }^{16}$ a validated form including ratings of eight symptoms commonly reported after surgery: nausea, retching, headache, abdominal pain, tiredness, drowsiness, blurred vision and itching, was used to assess the postoperative symptoms. To estimate overall discomfort a postoperative symptom sum score of the eight symptoms was calculated (minimum sum score 8 , maximum 32 ). The higher the sum score, the more discomfort the patient experienced. The participant was also asked to report the pain intensity in the surgical area at peak and on average on the particular day, rated on a seven-point Likert-type scale.

Anxiety, depression and pain sensitivity are factors that may influence postoperative recovery. In order to assess the balance of these conditions between the groups the participants completed the Hospital Anxiety and Depression Scale form and the Pain Sensitivity Questionnaire preoperatively after information of allocated treatment. ${ }^{17,18}$ Statistical analyses 
Sample size estimation was based on the primary outcome measure of quality of life, the EQ5D health index. With an $\alpha=0.05$ and $1-\beta=0.90$, the sample size was estimated to be 50 women including a drop-out of $10 \%$, based on the assumption that the EQ-5D health index differed by at least 0.2 units between the two groups, given the standard deviation of the EQ5D index (0.2) obtained from previous published data from our institution. ${ }^{19}$

Pearson Chi-square and Fisher's exact test were used to analyze categorical data. Continuous data were analyzed by means of Mann-Whitney U-test. Repeated measures ANOVA models were applied to analyze continuous data measured on more than two occasions. Since perioperative complications may influence recovery, the outcomes were adjusted for perioperative complications occurring before and after discharge. Consequently, it was necessary to divide the timing into two periods in the repeated measures ANOVA models; the first period from day 0 (dag of surgery) until day 4 when all women had been discharged, and the second period from day 5 until day 42. Kaplan-Meier survival analysis and the Cox proportional-hazard model were used to evaluate the occurrence of complications. The significance level was set at $p<0.05$. All analyses were carried out according to intention-to-treat principles.

The Software STATISTICA 64 version 13.2 (Dell Software, 5 Polaris Way, Aliso Viejo, CA 92656, USA) was used to carry out the statistical analyses.

\section{Ethical approval}

The Regional Ethical Review Board in Linköping, Sweden approved the trial (Dnr 2011/10831). The study was registered in ClinicalTrial.gov (NCT 01526655). 


\section{Results}

The flowchart of the study participants is presented in Figure 1. Twenty-four women randomized to abdominal and 25 to robotic hysterectomy completed the study.

The demographic and descriptive data are demonstrated in Table 1 and revealed a balanced distribution. The peri- and postoperative data including complications are shown in Table 2, revealing no differences between the groups except for a significant shorter operation time for the abdominal group.

The EQ-5D index between the robotic and abdominal hysterectomy group did not differ significantly in the period from day 0 to day 4 (Figure 2). The robotic hysterectomy group had a significantly faster recovery of the health-related quality of life in the period from day 5 to day 42 than the abdominal hysterectomy group, even when adjusted for complications. The women recovered to their preoperative level nearly two weeks earlier than the abdominal hysterectomy group.

The Short Form-36 showed that the groups had recovered evenly after six weeks (Table 3) except for the subscales of general health and social functioning, in robotic hysterectomy favor. When adjusted for complications on any occasion, only general health remained statistically significant (Mann-Whitney-U-test, $\mathrm{p}=0.04$ ) in the group without complications (RH, n=17 and $\mathrm{AH}, \mathrm{n}=12$ ).

The women in the robotic group presented significantly fewer symptoms postoperatively according to the symptom sum score than the abdominal group after discharge when adjusted for complications (SDC Figure 3). The reported pain intensity at peak did not differ significantly in the period from day 0 to day 4 between the groups, but was significantly lower in the robotic group in the period from day 5 to day 42. However, after adjustment for complications the significance vanished. No such differences were seen between the groups for the reported pain intensity on average (SDC Figure 4) in these periods. 
The consumption of opioids postoperatively was equally low in both groups and remained very low from day 1 onwards (SDC Figure 5). Likewise, the consumption of nonopioid analgesic revealed no significant differences between the groups.

There was no significant difference in the length of hospital stay from the time of arrival in the operation theater to discharge from the ward or in the time to meet the discharge criteria between the two groups (Table 2). However, for the women who had no complications during hospital stay $(\mathrm{RH}, \mathrm{n}=23$ and $\mathrm{AH}, \mathrm{n}=19)$ the time to meet the discharge criteria was significantly lower in the robotic group (median (range) 36 hours (30-60 hours) vs 36 hours (36-60 hours), Mann-Whitney U-test adjusted for ties, $\mathrm{p}=0.03$ ).

None of the patients needed conversion of the robotic operation to laparotomy. No major complications occurred in the robotic group, whereas one patient was re-operated in the abdominal group due to vaginal vault bleeding. Minor complications were numerically more prevalent in the abdominal group, as shown in Table 2. However, the Kaplan-Meier curve over time from discharge to occurrence of complications revealed no significant difference between the groups (SDC Figure 6). The perceived health-related quality of life showed a strong association with complications with lower EQ-5D health index in women with complications (SDC Figure 7). In the multivariate model, perioperative complications occurring before discharge were a significant independent risk factor in the period from day 0 to day 4 for lower EQ-5D health index $(\mathrm{p}=0.01)$, higher consumption of opioids $(\mathrm{p}<0.01)$, higher pain intensity on average $(p=0.03)$ and at peak $(p=0.01)$. Complications occurring after discharge from day 5 to day 42 were likewise a significant independent risk factor for the corresponding variables with comparable p-values but also for a higher symptom sum score $(\mathrm{p}<0.01)$ 


\section{Discussion}

This study showed that in an enhanced recovery after surgery setting robotic hysterectomy provided a faster recovery of the patient-reported health-related quality of life compared with abdominal hysterectomy in women with low-risk endometrial cancer. Six weeks postoperatively, the general health was significantly better for the women who had robotic hysterectomy without complications than for those who had abdominal. In this group, also hospital stay was shorter.

The strengths of this trial are the randomized design, the use of patient-reported experiences, medical measures, the enhanced recovery after surgery program and the adjustment of the results for complications in multivariate models. The preoperative assessment of factors that might influence postoperative recovery, such as anxiety, depression and pain sensitivity, strengthens the study. A limitation is the unblinded design and use of subjective outcomes. Because of the positive publicity concerning robotic surgery there is a risk of awareness bias in favor of robotic hysterectomy. The equality of outcomes in analgesic consumption, pain intensity between the two groups might indicate the possibility of such bias. Another limitation is the single center design and the fact that a single surgeon performed the robotic operations. This could increase the risk of selection bias. However, the patients were recruited consecutively and the final appointment for the surgery was made after they had agreed to participate in the study.

Robotic surgery has been compared in descriptive and retrospective studies with both laparoscopy and laparotomy treating endometrial cancer, mostly with focus on surgical aspects and complications, ${ }^{20}$ however, randomized trials are scarce ${ }^{9,10}$ and limited data are available on patient-reported outcomes and quality of life after robotic surgery. ${ }^{21}$ Herling et al. reported on health-related quality of life and symptoms after robotic hysterctomy in endometrial cancer by use of validated questionnaires including the EQ-5D, showing that 
quality of life and postoperative symtoms were negatively affected one week after surgery but had returned to the preoperative level five weeks after robotic hysterectomy. ${ }^{22}$ Like the study of Arms et al., showing improved quality of life measures within six weeks of robotic surgery, ${ }^{21}$ both trials were conducted as single-arm studies and lacked control groups. Available data for laparoscopy in treating endometrial cancer indicate a faster recovery of quality of life, in particular in the first month after surgery ${ }^{5}$ compared with abdominal surgery. The prospective trial by Ferguson et al. ${ }^{23}$ evaluating patient-reported outcomes and quality of life between laparoscopic, robotic, and open approaches for endometrial cancer showed improved health-related quality of life for minimal invasive surgery beyond the threeweek postoperative period, with noted benefits up to 12 weeks after surgery. This is in line with our trial. However the mean EQ-5D scores were not adjusted for postoperative complications and the surgery was not performed in an enhanced recovery after surgery setting. In our study no differences could be demonstrated between the groups in pain intensity, analgesic consumption and postoperative symptom score during hospital stay. This may indicate the positive effect of using the enhanced recovery after surgery protocol on postoperative recovery. ${ }^{24}$ Length of stay and time to meet the discharge criteria was equally short in both groups showing a difference between medical discharge criteria and contextspecific social circumstances or demography prolonging hospital stay. It is difficult to compare hospital stay in this trial with others in endometrial cancer ${ }^{8,20}$ because of various study designs and differently defined hospital stay. Several studies, in conformity with ours, have shown longer operation times for robotic hysterectomy compared with abdominal. ${ }^{6,25}$ This seems to reflect learning curve effects not only for the surgeon but for the whole operating team. ${ }^{26}$ Reports on learning curves for robotic hysterectomy differ widely from about ten to a large number of operations. ${ }^{26,27}$ The robotic surgeon in this study had performed more than 50 robotic procedures prior to the start of this trial. 


\section{Conclusion}

Robotic hysterectomy in an enhanced recovery after surgery program for treatment of lowrisk endometrial cancer led to a faster postoperative recovery of the health-related quality of life compared with abdominal. After six weeks, the health-related quality of life was still rated higher in the robotic group concerning the perception of general health. Hospital stay was equally short. However, complications significantly influenced the patient-reported healthrelated quality of life and hospital stay. This indicates that more efforts should be made to reduce perioperative complications.

\section{Acknowledgments}

Special thanks go to Shefqet Halili, MD, Department of Obstetrics and Gynecology, University Hospital, Linköping, who performed the robotic operations in this study, and the research nurses Åsa Rydmark Kersley, Linda Shosholli and Gunilla Gagnö for their dedicated work with the patients and on the project.

\section{Contribution to authorship}

The study was planned by PK, LN and NBW and conducted by all authors. Data were analysed by EL, PK and LN. EL is the main author of the draft. All authors (EL, PK, NBW and $\mathrm{LN}$ ) contributed to the interpretation of the results, the elaboration of the manuscript and approval of the final version.

\section{Funding}

The study was supported financially by grants from the Medical Research Council of South East Sweden, Linköping University and the County Council of Östergötland. 


\section{References}

1. Nelson G, Altman AD, Nick A, et al. Guidelines for pre- and intra-operative care in gynecologic/oncology surgery: Enhanced Recovery After Surgery (ERAS $®)$ Society recommendations--Part I. Gynecol Oncol. 2016;140(2):313-22.

2. Nelson G, Altman AD, Nick A, et al. Guidelines for postoperative care in gynecologic/oncology surgery: Enhanced Recovery After Surgery (ERAS®) Society recommendations--Part II. Gynecol Oncol. 2016;140(2):323-32.

3. Vlug MS, Wind J, Hollmann MW, et al. Laparoscopy in combination with fast track multimodal management is the best perioperative strategy in patients undergoing colonic surgery: a randomized clinical trial (LAFA-study). Ann Surg. 2011;254(6):86875.

4. Walker JL, Piedmonte MR, Spirtos NM, et al. Laparoscopy compared with laparotomy for comprehensive surgical staging of uterine cancer: Gynecologic Oncology Group Study LAP2. J Clin Oncol. 2009;27(32):5331-6.

5. He H, Zend D, Ou H, et al. Laparoscopic treatment of endometrial cancer: systematic review. J Minim Invasive Gynecol 2013; 20 (4):413-23.

6. O'Malley DM, Smith B, Fowler JM. The role of robotic surgery in endometrial cancer. $J$ Surg Oncol. 2015;112(7):761-8.

7. Nevis IF, Vali B, Higgins C, et al. Robot-assisted hysterectomy for endometrial and cervical cancers: a systematic review. J Robot Surg. 2017;11(1):1-16.

8. Kristensen SE, Mosgaard BJ, Rosendahl M, et al. Robot-assisted surgery in gynecological oncology: current status and controversies on patient benefits, cost and surgeon conditions - a systematic review. Acta Obstet Gynecol Scand. 2017;96(3):27485. 
9. Wijk L, Nilsson K, Ljungqvist O. Metabolic and inflammatory responses and subsequent recovery in robotic versus abdominal hysterectomy: A randomised controlled study. Clin Nutr. 2018;37(1):99-106.

10. Salehi S, Åvall-Lundqvist E, Legerstam B, et al. Robot-assisted laparoscopy versus laparotomy for infrarenal paraaortic lymphadenectomy in women with high-risk endometrial cancer: A randomised controlled trial. Eur J Cancer. 2017;79:81-9.

11. Swedish National Guidelines for Endometrial Cancer [In Swedish: Nationellt Vårdprogram för Endometriecancer].[cited December 28, 2018]. Available from:https://www.sfog.se/media/117538/natvp_endometricancer_nov2011.pdf

12. WHO Collaborating Centre for Drug Statistics Methodology. Definition and general considerations. [cited 2018, September 14]. Available from: https://www.whocc.no/ddd/definition_and_general_considera/

13. Caraceni A, Hanks G, Kaasa S, et al. Use of opioid analgesics in the treatment of cancer pain: evidence-based recommendations from the EAPC. Lancet Oncol. 2012;13(2):e58-68.

14. EuroQol Group. EuroQol--a new facility for the measurement of health-related quality of life. Health Policy. 1990;16(3):199-208.

15. Sullivan M, Karlsson J, Ware JE, Jr. The Swedish SF-36 Health Survey--I. Evaluation of data quality, scaling assumptions, reliability and construct validity across general populations in Sweden. Soc Sci Med. 1995;41(10):1349-58.

16. Alkaissi A, Gunnarsson H, Johnsson V, et al. Disturbing post-operative symptoms are not reduced by prophylactic antiemetic treatment in patients at high risk of postoperative nausea and vomiting. Acta Anaesthesiol Scand. 2004; 48(6):761-71.

17. Bjelland I, Dahl AA, Haug TT, et al. The validity of the Hospital Anxiety and Depression Scale. An updated literature review. J Psychosom Res. 2002;52(2):69-77. 
18. Ruscheweyh R, Marziniak M, Stumpenhorst F, et al. Pain sensitivity can be assessed by self-rating: Development and validation of the Pain Sensitivity Questionnaire. Pain. 2009; 146(1-2):65-74.

19. Wodlin NB, Nilsson L, Kjølhede P. Health-related quality of life and postoperative recovery in fast-track hysterectomy. Acta Obstet Gynecol Scand. 2011;90(4):362-8.

20. Park DA, Lee DH, Kim SW, et al. Comparitive safety and effectiveness of robotassisted laparoscopic hysterectomy versus conventional laparoscopy and laparotomy for endometrial cancer: A systematic review and meta-analysis. Eur J Surg Oncol. 2016; 42 (9):1303-14.

21. Arms RG, Sun CC, Burzawa JK, et al. Improvement in quality of life after robotic surgery results in patient satisfaction. Gynecol. Oncol. 2015; 138 (3):727-30.

22. Herling SF, Møller AM, Palle C, et al. Health-related quality of life after roboticassisted laparoscopic hysterectomy for women with endometrial cancer - A prospective cohort study. Gynecol Oncol. 2016;140(1):107-13.

23. Ferguson SE, Panzarella T, Lau S, et al. Prospective cohort study comparing quality of life and sexual health outcomes between women undergoing robotic, laparoscopic and open surgery for enometrial cancer. Gynecol Oncol. 2018; 149(3):476-83.

24. Lavand'homme P, De Kock M. The use of intraoperative epidural or spinal analgesia modulates postoperative hyperalgesia and reduces residual pain after major abdominal surgery. Acta Anaesthesiol Belg. 2006;57(4):373-9.

25. Mok ZW, Yong EL, Low JJ, et al. Clinical outcomes in endometrial cancer care when the standard of care shifts from open surgery to robotics. Int J Gynecol Cancer. 2012;22(5):819-25. 
26. Maenpaa M, Nieminen K, Tomas E, et al. Implementing robotic surgery to gynecologic oncology: the first 300 operations performed at a tertiary hospital. Acta Obstet Gynecol Scand. 2015;94(5):482-8.

27. Sandadi S, Gadzinski JA, Lee S, et al. Fellowship learning curve associated with completing a robotic-assisted total laparoscopic hysterectomy. Gynecol Oncol. 2014;132(1):102-6. 


\section{Figure legends}

Figure 1. Flow chart of participants in the study

Figure 2. EQ-5D health index from Day 0 to Day 42 


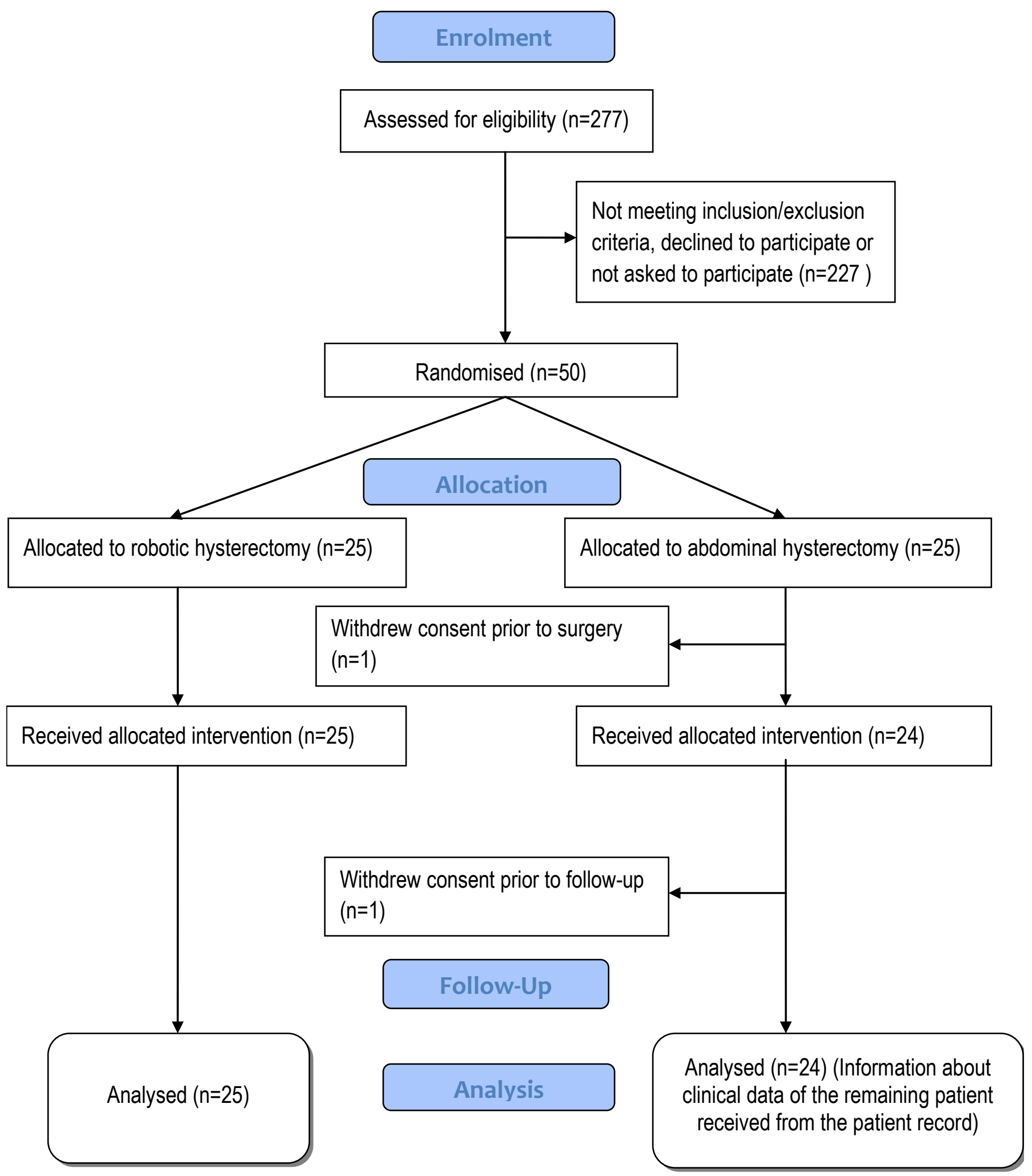

Figure 1. Flow chart of participants in the study. 

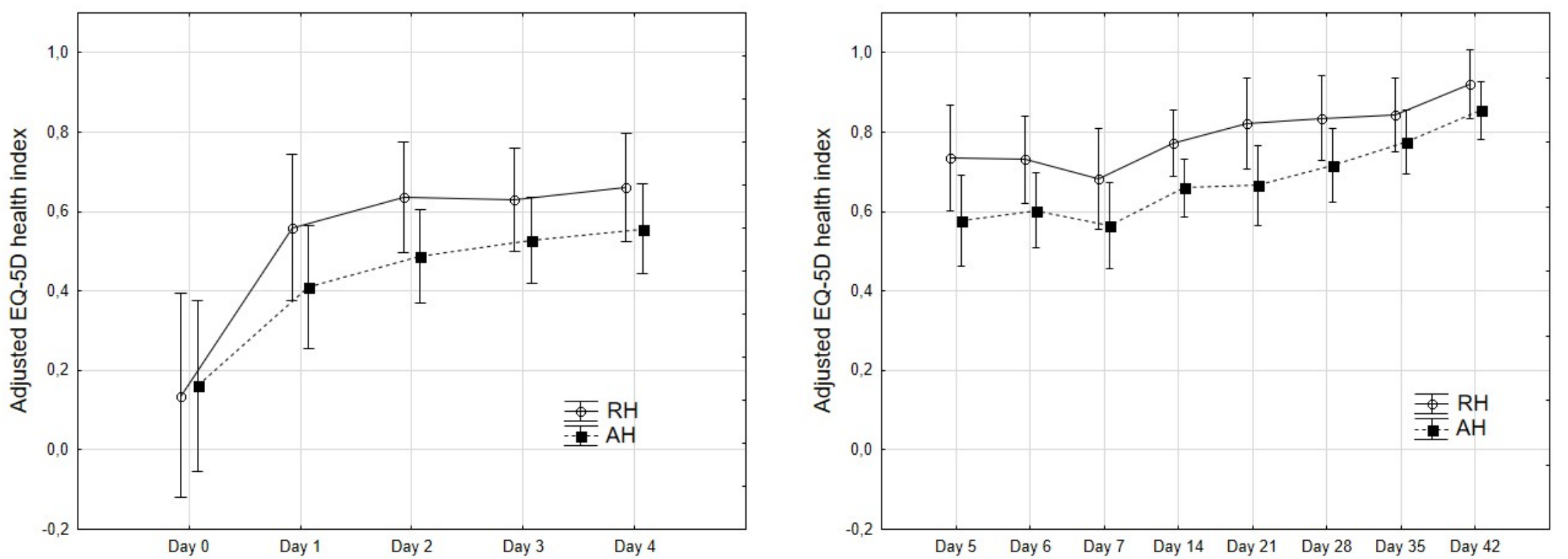

Repeated measures ANOVA

\begin{tabular}{llccc}
\cline { 2 - 5 } Timing & & Main effect between hysterectomy groups & Main effect over time & Interaction effect \\
\hline \multirow{2}{*}{ Day 0 to Day 4 } & Crude & $p=0.06$ & $p<0.0001$ & $p=0.44$ \\
& Adjusted & $p=0.18$ & $p<0.0001$ & $p=0.24$ \\
Day 5 to Day 42 & Crude & $p<0.01$ & $p<0.0001$ & $p=0.27$ \\
& Adjusted & $p=0.02$ & $p<0.0001$ & $p=0.47$ \\
\hline
\end{tabular}

Figure 2. EQ-5D health index from Day 0 to Day 42. Plots represent means and bars represent 95\% confidence intervals. Repeated measures ANOVA. Crude and adjusted p-values. The EQ-5D health index on Day 0 - 4 was adjusted for complications during hospital stay and on Day 5 - 42 was adjusted for complications during hospital stay and complications after discharge.

$\mathrm{AH}=$ abdominal hysterectomy; $\mathrm{RH}=$ robotic hysterectomy. 


\section{Listing Supplemental Digital Content}

SDC Figure 3. SPSQ sum score .word-doc

SDC Figure 4. Pain intensity .word-doc

SDC Figure 5. Analgesic consumption .word-doc

SDC Figure 6. Occurrence of complications .word-doc

SDC Figure 7. EQ-5D and complications .word-doc 

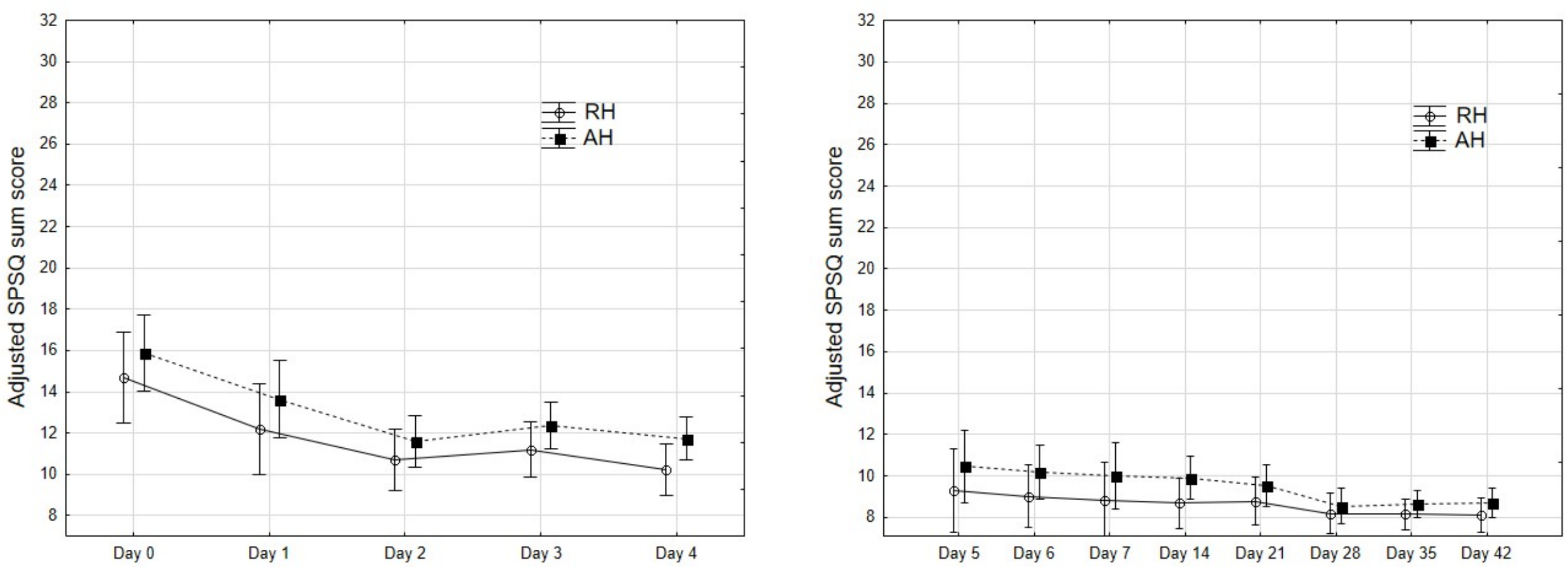

\begin{tabular}{|c|c|c|c|c|}
\hline \multirow[b]{2}{*}{ Timing } & \multicolumn{4}{|c|}{ Repeated measures ANOVA } \\
\hline & & Main effect between hysterectomy groups & Main effect over time & Interaction effect \\
\hline \multirow{2}{*}{ Day 0 to Day 4} & Crude & $p=0.02$ & $p<0.0001$ & $p=0.91$ \\
\hline & Adjusted & $p=0.06$ & $p<0.0001$ & $p=0.97$ \\
\hline \multirow{2}{*}{ Day 5 to Day 42} & Crude & $p<0.01$ & $p<0.0001$ & $p=0.16$ \\
\hline & Adjusted & $p=0.02$ & $p=0.04$ & $p=0.36$ \\
\hline
\end{tabular}

SDC Figure 3. SPSQ sum score from day 0 to day 42. Plots represent mean sum score and bars represent 95\% confidence interval. Repeated measures ANOVA. Crude and adjusted p-values. The SPSQ sum scores on Day 0 - 4 were adjusted for complications during hospital stay and on Day 5 - 42 were adjusted for complications during hospital stay and complications after discharge.

$\mathrm{AH}=$ abdominal hysterectomy; $\mathrm{RH}=$ robotic hysterectomy. 

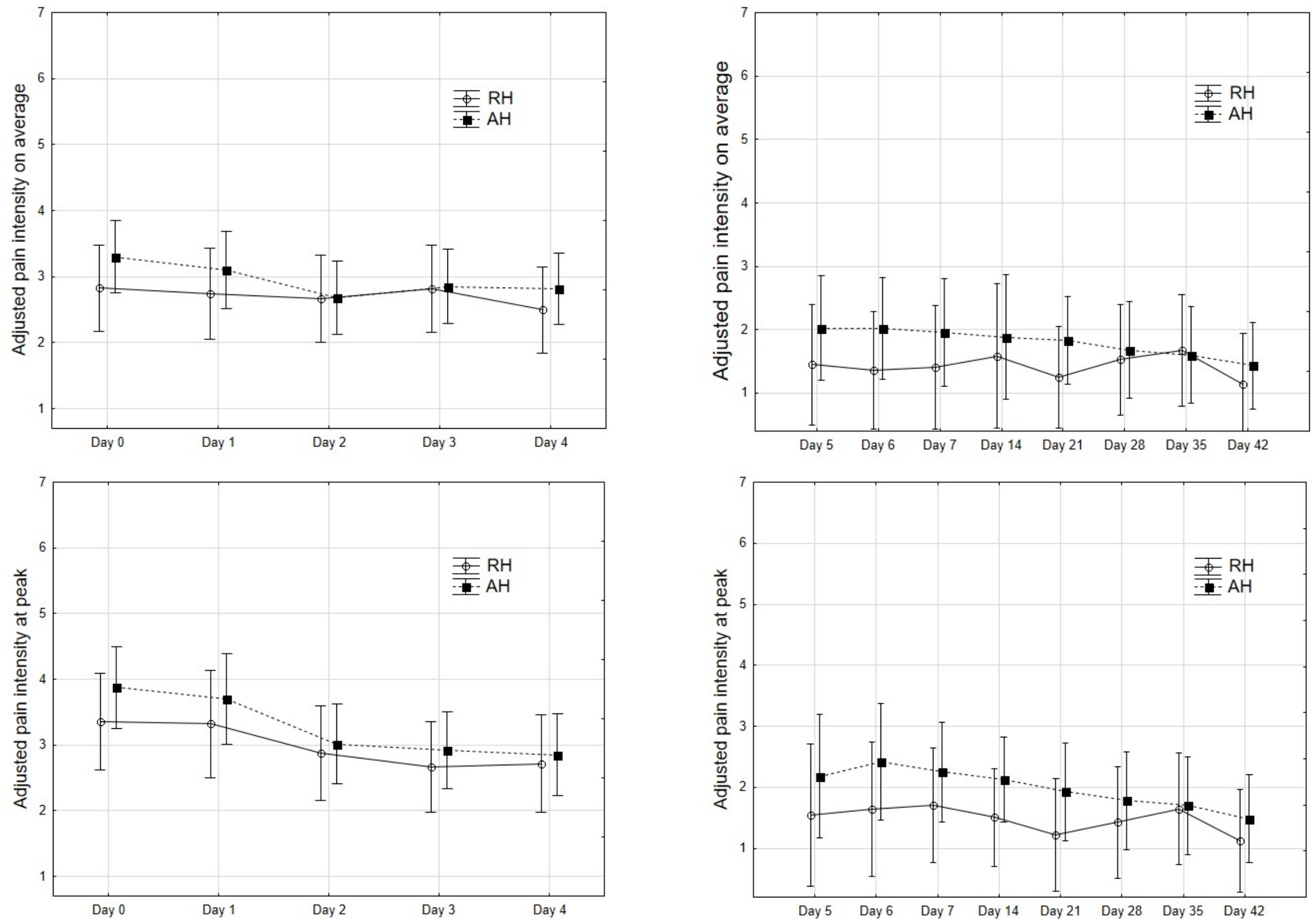
Repeated measures ANOVA

\begin{tabular}{|c|c|c|c|c|c|}
\hline Pain intensity & Timing & & Main effect between hysterectomy groups & Main effect over time & Interaction effect \\
\hline \multirow{4}{*}{ On average } & \multirow{2}{*}{ Day 0 to Day 4} & Crude & $p=0.15$ & $p=0.35$ & $p=0.17$ \\
\hline & & Adjusted & $p=0.37$ & $p=0.43$ & $p=0.54$ \\
\hline & Dav 5 to Rav 42 & Crude & $p=0.08$ & $p=0.01$ & $p=0.26$ \\
\hline & Day 5 to vay 42 & Adjusted & $p=0.12$ & $p=0.97$ & $p=0.27$ \\
\hline \multirow{4}{*}{ At peak } & \multirow{2}{*}{ Day 0 to Day 4} & Crude & $p=0.14$ & $p=0.20$ & $p=0.22$ \\
\hline & & Adjusted & $p=0.35$ & $p<0.01$ & $p=0.80$ \\
\hline & \multirow{2}{*}{ Day 5 to Day 42} & Crude & $p=0.04$ & $p<0.0001$ & $p=0.32$ \\
\hline & & Adjusted & $p=0.06$ & $p=0.56$ & $p=0.27$ \\
\hline
\end{tabular}

SDC Figure 4. Pain intensity on average and at peak after surgery. Plots represent mean intensity and bars represent $95 \%$ confidence intervals. Repeated measures ANOVA. Crude and adjusted p-values. The pain intensity on average and at peak on Day 0 - 4 was adjusted for complications during hospital stay and on Day 5 - 42 was adjusted for complications during hospital stay and complications after discharge. $\mathrm{AH}=\mathrm{abdominal}$ hysterectomy; $\mathrm{RH}=$ robotic hysterectomy. 

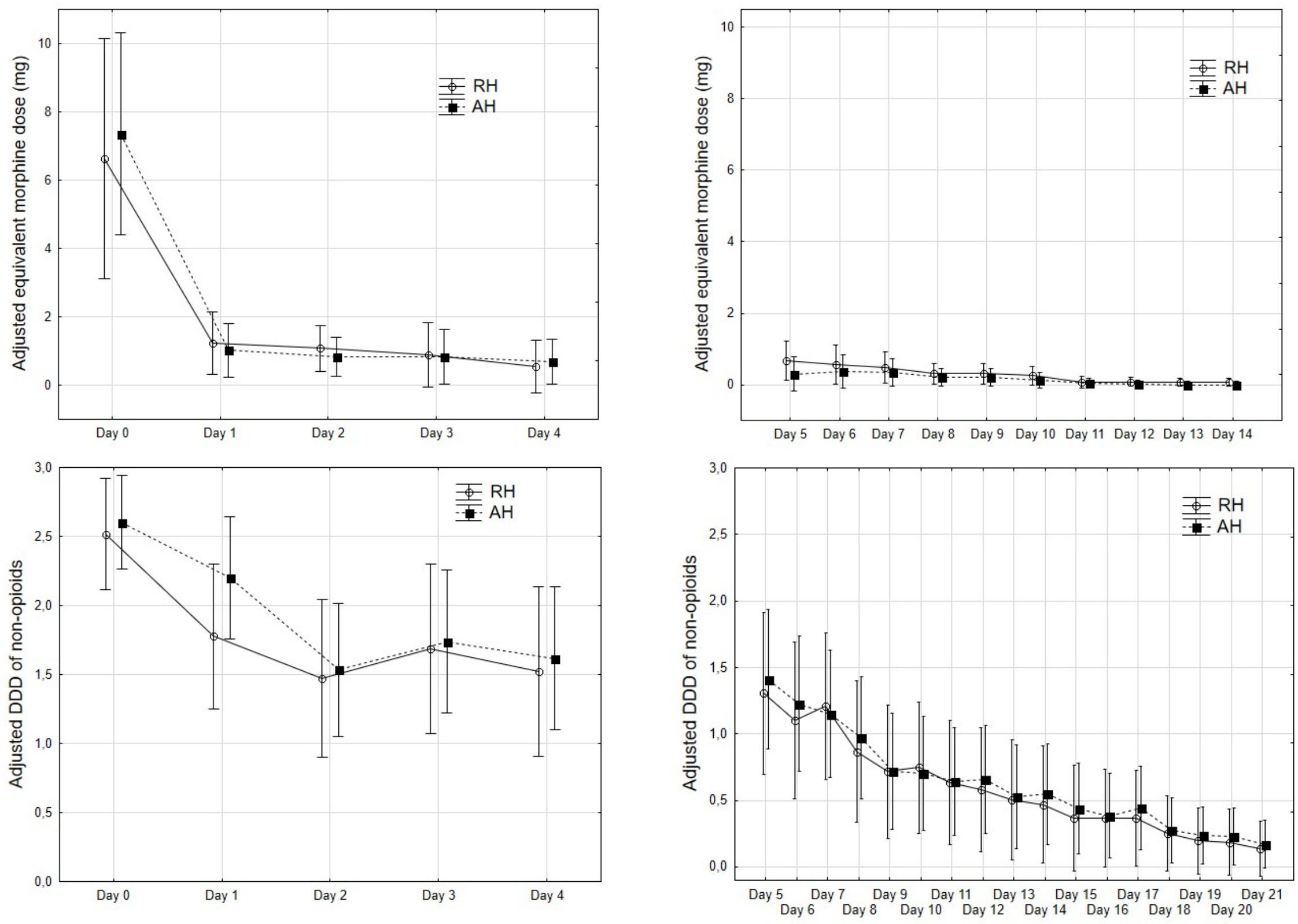
Repeated measures ANOVA

\begin{tabular}{|c|c|c|c|c|c|}
\hline & Timing & & Main effect between hysterectomy groups & Main effect over time & Interaction effect \\
\hline \multirow{4}{*}{ Equivalent morphine } & \multirow{2}{*}{ Day 0 to Day 4} & Crude & $p=0.36$ & $p=0.04$ & $p=0.09$ \\
\hline & & Adjusted & $p=0.89$ & $p<0.0001$ & $p=0.91$ \\
\hline & \multirow{2}{*}{ Day 5 to Day 14} & Crude & $p=0.78$ & $p<0.01$ & $p=0.96$ \\
\hline & & Adjusted & $p=0.40$ & $p<0.0001$ & $p=0.55$ \\
\hline \multirow{4}{*}{ DDD non-opioids } & \multirow{2}{*}{ Day 0 to Day 4} & Crude & $p=0.38$ & $p<0.0001$ & $p=0.70$ \\
\hline & & Adjusted & $p=0.46$ & $p<0.0001$ & $p=0.77$ \\
\hline & \multirow{2}{*}{ Day 5 to Day 21} & Crude & $p=0.79$ & $p<0.0001$ & $p=1.00$ \\
\hline & & Adjusted & $p=0.82$ & $p<0.0001$ & $p=1.00$ \\
\hline
\end{tabular}

SDC Figure 5. Equivalent morphine and DDD non-opioid consumption. Plots represent means and bars represent $95 \%$ confidence intervals. Repeated measures ANOVA. Crude and adjusted p-values. The analgesic consumptions on Day 0 - 4 were adjusted for complications during hospital stay and on Day 5 - 42 were adjusted for complications during hospital stay and complications after discharge. $\mathrm{AH}=$ abdominal hysterectomy; DDD = defined daily dose; $\mathrm{RH}$ = robotic hysterectomy. 
o Complete + Censored

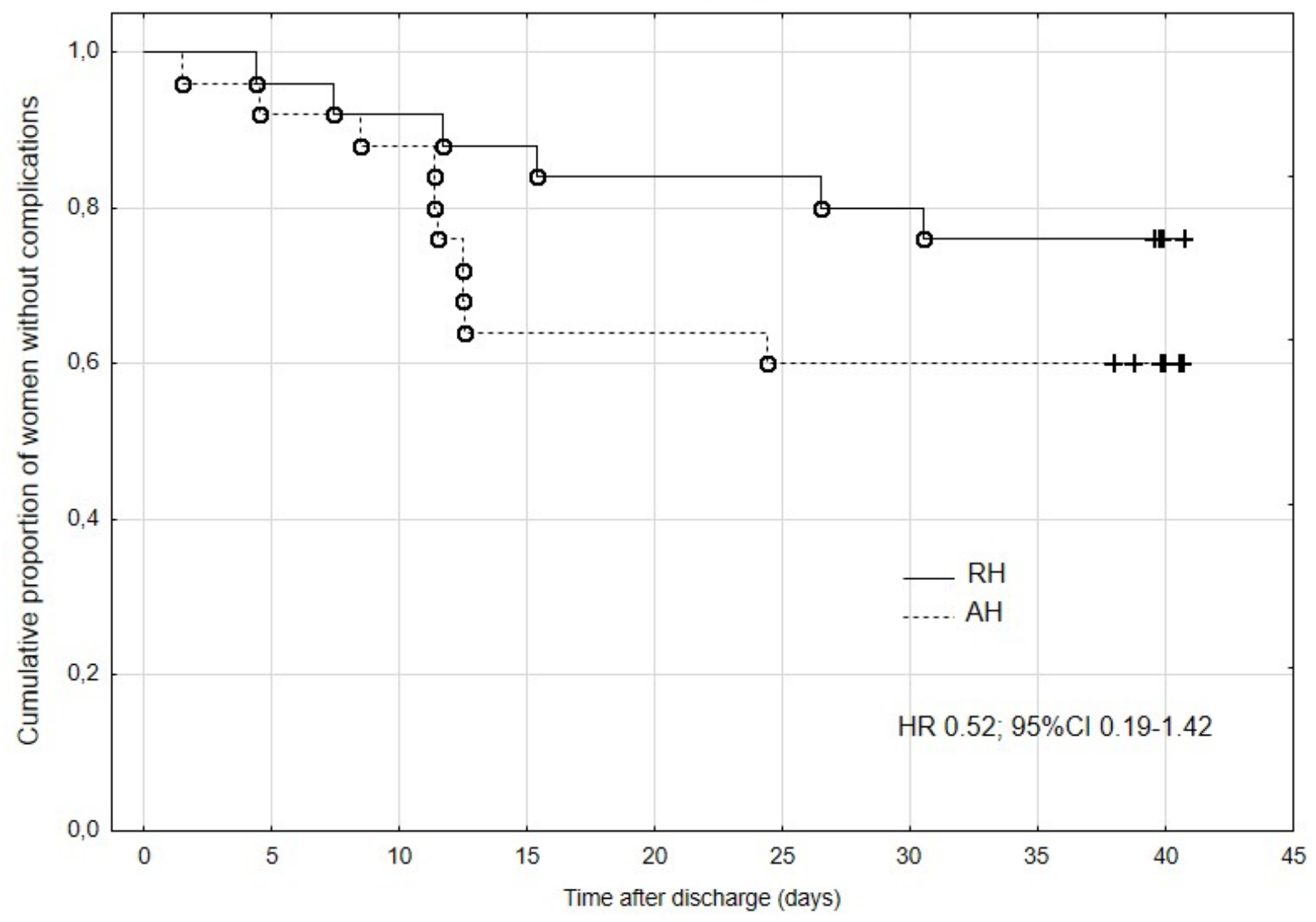

SDC Figure 6. The Kaplan-Meier curve of the cumulative proportion of women without complications in relation to period from time of discharge to occurrence of the adverse event in the two groups. Comparison was performed by means of the Cox Proportional Hazard Model. Results presented as hazard ratio (HR) and 95\% confidence interval (CI). 

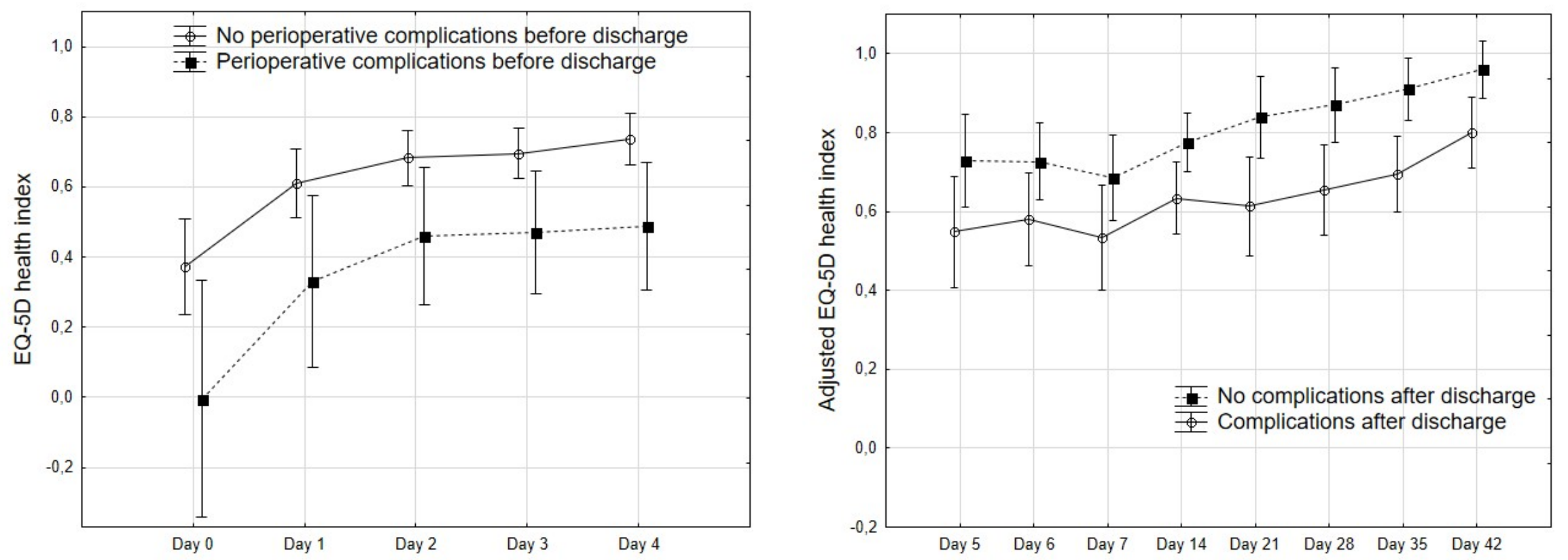

Repeated measures ANOVA

\begin{tabular}{llccc}
\cline { 2 - 4 } Timing & & Main effect between hysterectomy groups & Main effect over time & Interaction effect \\
\hline \multirow{2}{*}{ Day 0 to Day 4} & Crude & $p=0.01$ & $p<0.0001$ & $p=0.69$ \\
\multirow{2}{*}{ Day 5 to Day 42} & Crude & $p=0.001$ & $p<0.0001$ & $p=0.63$ \\
& Adjusted & $p=0.001$ & $p<0.0001$ & $p=0.53$ \\
\hline
\end{tabular}

SDC Figure 7. Association between complications and EQ-5D health index from Day 0 - 42. Plots represent means and bars represent 95\% confidence intervals. Repeated measures ANOVA. Crude and adjusted p-values. The EQ-5D health index on Day 5 - 42 was adjusted for complications during hospital stay. 
Table 1. Demographic and descriptive data.

\begin{tabular}{|c|c|c|c|}
\hline \multicolumn{2}{|l|}{ 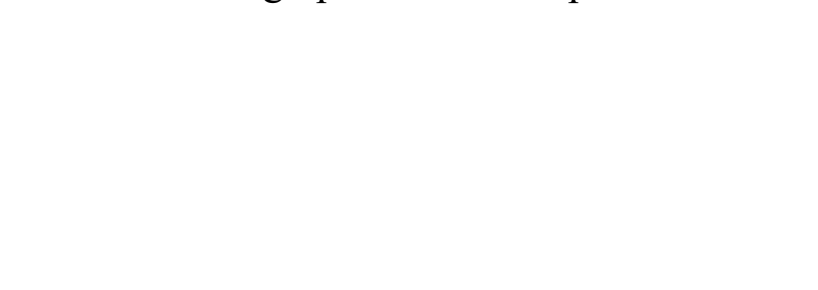 } & $\begin{array}{c}\text { Robotic } \\
\text { hysterectomy } \\
(\mathrm{n}=25) \\
\text { Number and }(\%) \\
\text { or } \\
\text { median (range) }\end{array}$ & $\begin{array}{c}\text { Abdominal } \\
\text { hysterectomy } \\
(n=25) \\
\text { Number and (\%) } \\
\text { or } \\
\text { median (range) }\end{array}$ \\
\hline \multicolumn{2}{|l|}{ Age (years) } & $68(38-83)$ & $67(45-85)$ \\
\hline \multicolumn{2}{|c|}{ Body mass index (kg/m²) } & $28.2(21.5-54.1)$ & $28.0(19.4-37.8)$ \\
\hline \multicolumn{2}{|l|}{$\mathrm{BMl}<25 \mathrm{~kg} / \mathrm{m}^{2}$} & $7(28 \%)$ & $8(32 \%)$ \\
\hline \multicolumn{2}{|l|}{ BMI $25-29.9 \mathrm{~kg} / \mathrm{m}^{2}$} & $8(32 \%)$ & $10(40 \%)$ \\
\hline \multicolumn{2}{|l|}{ BMI $30-35$ kg/m² } & $6(24 \%)$ & $5(20 \%)$ \\
\hline \multicolumn{2}{|l|}{$\mathrm{BMI}>35 \mathrm{~kg} / \mathrm{m}^{2}$} & $4(16 \%)$ & $2(8 \%)$ \\
\hline \multicolumn{2}{|l|}{ Parity } & $2(0-5)$ & $2(0-5)$ \\
\hline \multicolumn{2}{|l|}{ Smokers } & $4(16 \%)$ & $0(0 \%)$ \\
\hline \multicolumn{2}{|l|}{ Previous laparotomy } & $13(52 \%)$ & $8(32 \%)$ \\
\hline \multirow[t]{4}{*}{ Comorbidity: } & Cardiovascular disease & $10(40.0 \%)$ & $11(44 \%)$ \\
\hline & Pulmonary disease & $3(12 \%)$ & $3(12 \%)$ \\
\hline & Diabetes mellitus & $0(0 \%)$ & $4(16 \%)$ \\
\hline & Previous breast cancer & $3(12 \%)$ & $3(12 \%)$ \\
\hline \multirow[t]{2}{*}{ Current medication: } & Antidepressant/sedative & $2(8 \%)$ & $3(12 \%)$ \\
\hline & Analgesics & $5(20 \%)$ & $2(8 \%)$ \\
\hline \multirow[t]{3}{*}{ ASA classification: } & Class I & $9(36 \%)$ & $11(44 \%)$ \\
\hline & Class II & $15(60 \%)$ & $13(52 \%)$ \\
\hline & Class III & $1(4 \%)$ & $1(4 \%)$ \\
\hline \multicolumn{2}{|c|}{ EQ-5D health index preoperatively } & $0.81(0.12-1.00)$ & $0.82(0.12-1.00)$ \\
\hline \multirow[t]{3}{*}{ HADS Anxiety } & No anxiety & $13(52 \%)$ & $15(60 \%)$ \\
\hline & Mild-moderate anxiety & $9(36 \%)$ & $6(24 \%)$ \\
\hline & Severe anxiety & $3(12 \%)$ & $4(16 \%)$ \\
\hline \multirow[t]{2}{*}{ Depression } & No depression & $21(84 \%)$ & $21(84 \%)$ \\
\hline & Mild-moderate depression & $4(16 \%)$ & $4(16 \%)$ \\
\hline \multicolumn{2}{|l|}{ PSQ total score } & $2.9(1.6-6.6)$ & $3.3(0.4-6.6)$ \\
\hline \multicolumn{2}{|l|}{ PSQ minor score } & $2.1(0.6-5.0)$ & $2.3(0.3-7.3)$ \\
\hline \multicolumn{2}{|l|}{ PSQ moderate score } & $4.4(1.0-9.7)$ & $4.4(0.6-7.3)$ \\
\hline
\end{tabular}

ASA, American Society of Anesthesiologists risk classification; BMI, body mass index; EQ-5D, EuroQol Group form; HADS, Hospital Anxiety and Depression Scale; PSQ, Pain Sensitivity Questionnaire.

No statistically significant differences were found between the groups in the variables depicted in the table. 
Table 2. Peri- and postoperative data.

\begin{tabular}{|c|c|c|c|c|}
\hline & & $\begin{array}{c}\text { Robotic } \\
\text { hysterectomy } \\
(\mathrm{n}=25) \\
\text { Number and } \\
(\%) \text { or } \\
\text { median (range) }\end{array}$ & $\begin{array}{c}\text { Abdominal } \\
\text { hysterectomy } \\
(n=24) \\
\text { Number and } \\
(\%) \text { or } \\
\text { median } \\
\text { (range) }\end{array}$ & $\begin{array}{c}p- \\
\text { value } \\
*\end{array}$ \\
\hline \multicolumn{2}{|l|}{ Operation time ${ }^{\#}$ (minutes) } & $70(48-125)$ & $56(41-104)$ & 0.048 \\
\hline \multicolumn{2}{|c|}{ Estimated per-operative blood loss (ml) } & $50(20-150)$ & $50(10-250)$ & 0.68 \\
\hline \multicolumn{2}{|c|}{ Time in post anesthesia care unit (hours) } & $4.4(2.7-13.3)$ & $5.2(2.3-11.5)$ & 0.34 \\
\hline \multicolumn{2}{|c|}{ Length of hospital stay (de facto) (hours) } & $53(30-60)$ & $51(32-98)$ & 0.16 \\
\hline \multicolumn{2}{|c|}{ Length of hospital stay (when discharge criteria met) (hours) } & $36(30-60)$ & $36(30-60)$ & 0.27 \\
\hline \multirow[t]{3}{*}{ Final histopathological diagnosis } & FIGO grade $1 \mathrm{EC}$ & $15(60 \%)$ & $11(46 \%)$ & \\
\hline & FIGO grade 2 EC & $9(36 \%)$ & $10(42 \%)$ & $0.44^{a}$ \\
\hline & FIGO grade 3 EC & $1(4 \%)$ & $3(12 \%)$ & \\
\hline \multirow[t]{4}{*}{ Surgical FIGO stage } & IA & $18(72 \%)$ & $15(63 \%)$ & \\
\hline & IB & $4(16 \%)$ & $7(29 \%)$ & 070 a \\
\hline & II & $1(4 \%)$ & $1(4 \%)$ & 0.10 \\
\hline & IIIA & $2(8 \%)$ & $1(4 \%)$ & \\
\hline \multicolumn{2}{|c|}{ Adverse events during hospital stay (no. of women) } & $2(8 \%)$ & $5(21 \%)$ & $0.25^{b}$ \\
\hline \multicolumn{2}{|c|}{ Bladder injury } & & 1 & \\
\hline \multicolumn{2}{|c|}{ Spinal puncture not possible } & 1 & 2 & \\
\hline \multicolumn{2}{|l|}{ Intubation difficulties } & & 1 & \\
\hline \multicolumn{2}{|l|}{ Vaginal vault hematoma } & & 1 & \\
\hline \multicolumn{2}{|c|}{ Red blood cell transfusion } & & 1 & \\
\hline \multicolumn{2}{|c|}{ Urinary catheter not settled at discharge } & & 1 & \\
\hline \multicolumn{2}{|c|}{ Neuralgia } & 1 & & \\
\hline \multicolumn{2}{|c|}{ Adverse events after discharge until follow-up (no. of women) } & $6(24 \%)$ & $10(42 \%)$ & $0.19 a$ \\
\hline \multicolumn{2}{|c|}{ Re-operation due to vaginal vault bleeding } & & 1 & \\
\hline \multicolumn{2}{|c|}{ Minor wound complications§ } & & 6 & \\
\hline \multicolumn{2}{|l|}{ Lower urinary tract infection } & 2 & 3 & \\
\hline \multicolumn{2}{|l|}{ Constipation } & & 2 & \\
\hline \multicolumn{2}{|l|}{ Pain/neuralgia } & 4 & 1 & \\
\hline
\end{tabular}

EC endometrioid adenocarcinoma. FIGO International Federation of Gynecology and Obstetrics.

\# time from skin open to skin closure; *Mann-Whitney U-test applied for continuous data and

${ }^{\text {a }}$ Pearson $\chi 2$ - test $(\mathrm{df}=1, \mathrm{df}=2$ or $\mathrm{df}=3)$ or ${ }^{\mathrm{b}}$ Fisher's exact test for categorical data. ${ }^{\S}$ Minor wound complications comprise superficial infection, seroma and superficial wound rupture. 
Table 3. SF-36 subscales and summary scores. A high score represents a better health-related quality of life.

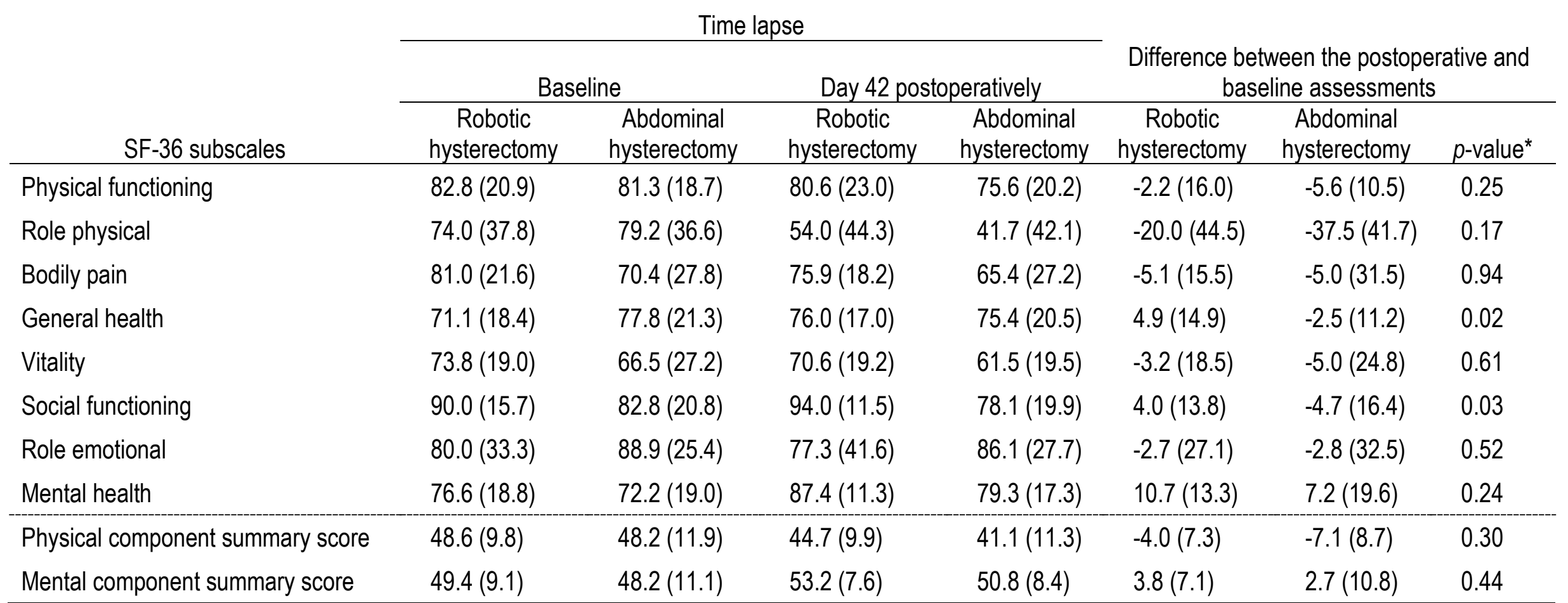

Figures indicate mean (1 SD).

No significant differences were observed in subscales between the two groups at baseline preoperatively (Mann-Whitney U-test).

* Mann-Whitney U-test, $p$-values adjusted for ties. 